\title{
Output Convergence and International Trade: Time-Series and Fuzzy Clustering Evidence for New Zealand and Her Trading Partners, 1950-1992
}

\author{
David E. A Giles
}

Department of Economics

University of Victoria

June 2001

\begin{abstract}
Using historical time-series data, we test for convergence and common trends in real per capita output for New Zealand and her four major trading partners. Both bivariate and multivariate time-series methods are used, and we also implement the fuzzy c-means clustering algorithm as an alternative basis for detecting convergence. The results of our time-series analysis accord with earlier studies - we find limited evidence of (only bivariate) convergence, but ample evidence of a small number of common trends.

In contrast, our fuzzy clustering analysis reveals very strong evidence of a particular form of output convergence when the five trading countries are considered as a group.
\end{abstract}

\section{Keywords}

Economic growth, international trade, convergence, common trends, cointegration, fuzzy sets, pattern recognition

\section{Contact Information}

David E. A. Giles, Department of Economics, University of Victoria, P.O. Box 1700, STN CSC, Victoria, B.C., CANADA, V8W 2 Y2

FAX: (250) 721-6214; Voice: (250) 721-8540; email: dgiles@uvic.ca 


\section{Introduction}

In recent years a substantial empirical literature has emerged in relation to testing for the convergence of per capita output across different economies. Essentially, this literature may be viewed as a test of the prediction of the neoclassical growth model (Solow, 1956), as opposed to that of the "new" (endogenous) growth models (e.g., Romer, 1986; Lucas, 1988). Broadly speaking, the neoclassical model predicts (under rather strong assumptions) that per capita output in an economy will converge to the same level, regardless of the initial capital endowment. On the other hand, the "new" growth models incorporate features (such as production nonconvexities) that permit the emergence of multiple equilibria in long-term output paths, so that similarly endowed economies need not converge.

Empirical testing of the convergence hypothesis has been based on both cross-section and timeseries data. In the former case, a negative correlation (across countries) between initial per capita output levels and subsequent growth rates is interpreted as evidence in favour of so-called "betaconvergence". In the latter case, (stochastic) convergence implies that output differences between economies cannot contain unit roots or time trends, and the output levels in different countries must be cointegrated. The empirical results have been extremely mixed - on balance, those associated with cross-section data have tended to favour convergence, while those based on timeseries data have not. For further details, see Baumol (1986), Dowrick and Nguyen (1989), Barro (1991), Mankiw et al. (1992), Bernard (1992), Quah (1993), Barro and Sala-i-Martin (1991, 1992, 1995), Bernard and Durlauf (1995, 1996), Greasley and Oxley (1997), Cellini and Scorcu (2000), among others, and the excellent survey by Durlauf and Quah (1999). St. Aubyn (1999, p.24) offers some explanations for the apparent discrepancy between the cross-section and timeseries evidence. In addition to cointegration testing he also uses a procedure based on the Kalman filter, and with the latter he finds evidence of convergence, after World War 2, between the U.S.A. and every G-7 country except Canada.

Interestingly, and as Slaughter (1997) has noted, this literature on testing for convergence has largely ignored the role of international trade. For instance, in a "Solow world" countries exist independently of each other, and so international linkages such as trade, factor mobility and the transfer of technology cannot be considered. Convergence in output arises as a result of convergence in per capita capital stock. In contrast, some authors have focussed on the empirical connection between international trade and output convergence. Recent examples include Ben- 
David (1993, 1996), and Sachs and Warner (1995), who find historical periods of convergence among economies that either started out by being relatively open with respect to each other, have high trade volumes, or liberalized their trade policies. Similarly, Ben-David and Kimhi (2000) provide evidence that an increase in trade between major trading partners (especially increased exports by poorer countries to their wealthier trading partners) is related to an increase in output convergence. Slaughter (1997) points out that the existence of convergence among trading partners does not imply that trade causes convergence. He also discusses (and critiques) potential ways in which trade and convergence may be linked: via factor-price equalization; by international flows of technology; and by trade in capital goods. On the negative side, O'Rourke (1996) finds that migration was more important than trade for international convergence in the late nineteenth century; and Bernard and Jones (1996) conclude that freer trade diverges incomes cross countries. Using a "difference in differences" methodology developed by Meyer (1994), Slaughter (1998) finds that various post-1945 trade liberalizations appear to have led to income divergence, rather than convergence.

Trade theory provides an ambiguous answer to the question, "Does increased international trade lead to per capita output (income) convergence across different economies?" The precise mechanisms linking trade and convergence are unclear, as are the relative contributions of traderelated and non-trade factors. In this paper we do not attempt to address the above question, per $s e-$ this is the subject of other research in progress. Instead, we search for more positive timeseries-based convergence results than have typically been found, by concentrating on a very open group of economies with a high degree of trade-dependence, and by considering a new methodological approach. More specifically, we consider the case of New Zealand and her four major trading partners over the period 1950 to 1992. These partners were Australia, Japan, the United Kingdom, and the U.S.A.. Our data are per capita GDP, in 1985 international prices and adjusted for terms of trade, taken from the Penn World Tables (Summers and Heston, 1995). The (logarithms of the) data are plotted in Figure 1. As can be seen there, each series is quite strongly trended, with no significant structural breaks (except perhaps for a shift in the trend of the Japanese series in 1973-74.

In addition to considering some established time-series tests for both bilateral and multilateral output convergence, we also demonstrate the use of "fuzzy clustering" techniques as an alternative way of measuring convergence. This particular approach has not been used previously to examine convergence, although alternative classification and clustering notions have been 
adopted in this context by Durlauf and Johnson (1995) and Hobijn and Franses (1999). Our fuzzy clustering results provide an interesting contrast with those from the more conventional timeseries analysis. The various tests that we use are described in sections 2 and 3, and the corresponding results appear in sections 4 and 5. The final section offers some conclusions and suggestions for further research.

\section{Convergence and Common Trends}

Bernard and Durlauf (1995, p.99) define stochastic convergence in output as follows.

If $y_{i, t}$ is log real per capita output for country $i$ at time $t$, and $I_{t}$ is the information set at time $t$, then countries $p=1,2, \ldots . ., n$ converge if the long-term forecasts of outputs for all countries are equal at a fixed time $t$ :

$$
\underset{k \rightarrow \infty}{\operatorname{Limit}} E\left(y_{1, t+k}-y_{p, t+k} \mid I_{t}\right)=0 ; \forall p \neq 1
$$

When $\mathrm{p}=2$, for example, this definition of convergence requires that the two countries' outputs must be cointegrated, with a cointegrating vector $[1,-1]$. So, in practice convergence would be rejected if the series $\left(\mathrm{y}_{\mathrm{i}}-\mathrm{y}_{\mathrm{j}}\right)$ contains a unit root, and we consider two types of unit root tests in our analysis below. In the multivariate case, convergence requires that there must be $(\mathrm{p}-1)$ cointegrating vectors of the form $[1,-1]$ or one common long-term trend. Accordingly, we can test for convergence by constructing a time-series based on the $(\mathrm{p}-1)$ deviations, $D \mathrm{y}_{\mathrm{i}, \mathrm{t}}=\left(\mathrm{y}_{1, \mathrm{t}}-\mathrm{y}_{\mathrm{i}, \mathrm{t}}\right)$, applying Johansen's (1988) multivariate cointegration analysis, and using his likelihood ratio "trace test" to determine the rank of the cointegrating matrix.

If the output series do not converge, they may still have common trends, and there may be a small number of stochastic trends affecting output which differ across countries (Bernard and Durlauf, 1995, pp. 99-100). Countries $\mathrm{p}=1,2, \ldots ., \mathrm{n}$ contain a single common trend if the long-term forecasts of output are simply proportional at a fixed time $\mathrm{t}$ :

$$
\underset{k \rightarrow \infty}{\operatorname{Limit}} E\left(y_{1, t+k}-\alpha_{p}{ }^{\prime} y_{, t+k} \mid I_{t}\right)=0
$$

where $\mathrm{y}_{\mathrm{t}}{ }^{\mathrm{N}}=\left(\mathrm{y}_{2, t}, \mathrm{y}_{3, t}, \ldots . ., \mathrm{y}_{\mathrm{p}, t}\right)$. When $\mathrm{p}=2$, for example, countries $\mathrm{i}$ and $\mathrm{j}$ have a common trend if $y_{i}$ and $y_{j}$ are cointegrated with a cointegrating vector $[1,-\alpha]$, and this is readily tested using the 
Engle-Granger (1987) procedure. In the multivariate case, Johansen's maximum likelihood analysis can again be used in conjunction with the original output data for all of the countries to determine the number of cointegrating vectors (common trends).

Using data for fifteen OECD countries over the period 1900 to 1987, Bernard and Durlauf (1995) find little evidence of convergence, but strong evidence of common trends. For all countries as a group, they conclude that there are three to six long-run shocking forces that help to determine economic growth; and four or five long-run processes for the outputs of the eleven European countries. So, economic growth cannot be explained simply by country-specific factors. There appears to be a small group of common long-run characteristics that (together with the countryspecific features) determine international growth rates. On can conjecture that international trade may play a role in the transmission and linking of these common factors.

Greasley and Oxley (1997), St. Aubyn (1999) and Cellini and Scorcu (2000) focus on the bivariate case $(\mathrm{p}=2)$ in their application of Bernard and Durlauf's analysis, and they emphasise the need to take account of structural breaks in the data when using unit root tests to test for convergence. Using Perron's (1989) modification of the Dickey-Fuller $(1979,1981)$ unit root test (and the same data as Bernard and Durlauf), Greasley and Oxley (1997) find evidence of bivariate convergence between Belgium and the Netherlands, France and Italy, Australia and the United Kingdom, and Sweden and Denmark. St. Aubyn's (1999) analysis also allows for exogenous structural breaks in the data. Of the countries and time-period that we are concerned with in our own study, he finds evidence of (pair-wise) convergence between the U.S.A. and each of the United Kingdom, Australia, and Japan using his Kalman filter methodology. He also finds evidence of stochastic convergence between the U.S.A. and Japan using bivariate cointegration testing. Also focussing on the latter approach, Cellini and Scorcu (2000) allow for endogenous structural breaks by means of the Gregory and Hansen (1996) test, and for our countries and timeperiod they detect stochastic convergence only for the U.S.A. and Canada, and the U.S.A. and the United Kingdom.

\section{Fuzzy Clustering}

One of the novel features of this paper is that we propose using "fuzzy sets" to cluster the output data for the different countries, and then track the distance between the centres of these clusters over time. If the centres of the fuzzy clusters move towards each other over time, this represents a 
particular type of convergence in output. We will refer to this as "cluster convergence". As this type of analysis has not been used previously in this context, a somewhat detailed discussion is warranted.

The theoretical basis for fuzzy sets is usually attributed to Zadeh (1965). In conventional set theory, elements either belong to some particular set or they do not. Another way of expressing this is to say that the "degree of membership" of a particular element with respect to a particular set is either unity or zero. The boundaries of the sets are "crisp". In contrast, in the case of fuzzy sets, the degree of membership may be any value on the continuum between zero and unity, and any particular element is associated with more than one set. Generally this association involves different degrees of membership with each of the fuzzy sets.

In our analysis we need to determine the partitioning of the output data for each country into a number of clusters, year by year. These clusters have "fuzzy" boundaries, in the sense that each data value belongs to each cluster to some degree or other. Having decided upon the number of such clusters to be used, some procedure is then needed to locate their mid-points and to determine the associated membership functions and degrees of membership for the data-points. We follow Giles and Draeseke (2001) and use a variant of the "fuzzy c-means" (FCM) algorithm. This algorithm apparently dates from Ruspini (1970), although some of the underlying concepts were explored by MacQueen (1967). The FCM algorithm is closely associated with such early contributors as Bezdek (1973) and Dunn $(1974,1977)$, and is widely used in such fields as pattern recognition.

The algorithm provides a method of dividing up the " $n$ " data-points into " $c$ " fuzzy clusters (where $c<n$ ), while simultaneously determining the locations of these clusters in the appropriate space. The metric that forms the basis for the usual FCM algorithm is "squared error distance", and the mathematical basis for this procedure is as follows. Let $\boldsymbol{x}_{k}$ be the $k^{\prime}$ th (possibly vector) data-point $(k=1,2, \ldots, n)$. Let $\mathbf{v}_{\mathrm{i}}$ be the center of the $i$ 'th. (fuzzy) cluster $(i=1,2, \ldots ., c)$. Let $d_{i k}=\left\|\boldsymbol{x}_{k}-\boldsymbol{v}_{i}\right\|$ be the distance between $\boldsymbol{x}_{k}$ and $\boldsymbol{v}_{i}$, and let $u_{i k}$ be the "degree of membership" of data-point " $k$ " in cluster " $i$ ", where :

$$
\sum_{i=1}^{c}\left(u_{i k}\right)=1
$$


The objective is partition the data-points into the " $c$ " clusters, and simultaneously locate those clusters and determine the associated "degrees of membership", so as to minimize the functional

$$
J(U, v)=\sum_{i=1}^{c} \sum_{k=1}^{n}\left(u_{i k}\right)^{m}\left(d_{i k}\right)^{2} .
$$

There is no prescribed manner for choosing the exponent parameter, " $m$ ", which must satisfy $1<$ $m<\infty$. In practice, $m=2$ is a common choice. In the case of crisp (hard) memberships, $m=1$.

The FCM algorithm involves the following broad steps:

1. Select the initial location for the cluster centres.

2. Generate a (new) partition of the data by assigning each data-point to its closest cluster centre.

3. Calculate new cluster centres as the centroids of the clusters.

4. If the cluster partition is stable then stop. Otherwise go to step 2 above.

In the case of fuzzy memberships, the Lagrange multiplier technique generates the following expression for the membership values to be used at step 2 above:

$$
u_{i k}=1 /\left\{\sum_{j=1}^{n}\left[\left(d_{i k}\right)^{2} /\left(d_{j k}\right)^{2}\right]^{1 /(m-1)}\right\} .
$$

If the memberships of data-points to clusters are "crisp" then

$$
\begin{aligned}
& u_{i k}=0 ; \forall i \neq j, \\
& u_{j k}=1 ; \text { j s.t. } d_{j k}=\min .\left\{d_{i k}, \mathrm{i}=1,2, \ldots ., c\right\} .
\end{aligned}
$$

The updating of the cluster centres at step 3 above is obtained via the expression

$$
v_{i}=\left[\sum_{k=1}^{n}\left(u_{i k}\right)^{m} x_{k}\right] /\left[\sum_{k=1}^{n}\left(u_{i k}\right)^{m}\right] ; i=1,2, \ldots, c .
$$

The fixed-point nature of this problem ensures the existence of a solution. See Bezdek (1981, Chapter 3) for more complete mathematical details. The FCM algorithm is simple to program, and we have used SHAZAM (2001) programming commands from Giles and Draeseke (2001) in this application. Once the centres of the fuzzy clusters have been determined, each of the " $n$ " data-points can be allocated to the cluster with the closest centre. In our application we have $n=5$ 
countries, which severely constrains the number of clusters that can be considered. Accordingly we consider $\mathrm{c}=2$ and $\mathrm{c}=3$.

\section{Results of Stochastic Convergence Tests}

In Table 1 we show the results of testing for unit roots in each of the (log) output series, allowing for the possibilities of $\mathrm{I}(2)$, I(1) or I(0) processes. We have used both the "augmented" DickeyFuller (ADF) tests, in which the null hypothesis is non-stationarity, and the tests of Kwiatowski et al. (KPSS) (1993) in which the null hypothesis is stationarity. We have used a 10\% significance level to compensate for the low powers of these tests, although the results are not sensitive to this choice.

In applying the ADF tests, the augmentation level ("L") has been chosen by the default method in the SHAZAM (2001) package, as Dods and Giles (1995) show that this approach leads to low size-distortion when "pre-testing" in samples of our size. We have used the sequential strategy of Dolado et al. (1990) to determine the inclusion/exclusion of drift and trend terms in the DickeyFuller regressions. In Table $1, \mathrm{t}_{\mathrm{dt}}$ denotes the ADF unit root "t-test" with drift and trend terms included in the fitted regression; $F_{u t}$ is the corresponding ADF "F-test" for a unit root and zero trend; $t_{d}$ is the unit root "t-test" with a drift but no trend in the fitted regression; $F_{u d}$ is the corresponding "F-test" for a unit root and a zero drift; and $t$ is the ADF unit root test when the fitted regression has no drift or trend term included. Finite-sample critical values for our "t-tests" and "F-tests" come from MacKinnon (1991), and from Dickey and Fuller (1979, 1981), respectively. The results in Table 1 clearly indicate that all of the series are I(1). Applying Perron's (1989) unit root test to allow for the possible structural break in the trend for Japanese output did not alter this conclusion.

In the case of the KPSS tests we have used values for the Bartlett window parameter, $l$, based on both the " $l 4$ rule" and the " $l 12$ rule". The " $l k$ rule" sets $l(k)=$ int. $\left[\mathrm{k}(\mathrm{T} / 100)^{1 / 4}\right]$, so this implies $l=3$ and $l=9$, for $\mathrm{k}=4$ and $\mathrm{k}=12$ respectively, for our sample size. KPSS give asymptotic critical values for the test with null hypotheses of both level-stationarity and trend-stationarity. Cheung et al. (1995) provide response-surface results that allow us to calculate finite-sample critical values in the trend-stationary case for any $l$ values, and more recently Hornok and Larsson (2000) provide exact critical values for both null cases and our choices of $l$. The KPSS results in Table 1 confirm that all of the series are I(1) - the null of level-stationarity is rejected at the $10 \%$ (and 5\%) 
level for all series; and the null of trend-stationarity is rejected at the $10 \%$ level in all cases except for the United Kingdom.

So, there is the possibility of cointegration between these series, and we test for this both pairwise and for the five output series as a group. As noted earlier, in the pair-wise case the existence of cointegration implies that the two series have common trends. Moreover, if the cointegrating vector is $[1,-1]$ then the two series converge. Following Greasley and Oxley (1997), we test the latter by testing for a unit root in the (log-) difference between a pair of series. The results (again based on both the ADF and KPSS tests) appear in Table 2, and we see that there is very little evidence of convergence. The ADF results suggest stochastic convergence between the output of Japan and those of each of the United Kingdom and the U.S.A. (and possibly also Australia and New Zealand); while the KPSS results suggest convergence between Australia and the United Kingdom, and possibly between New Zealand and each of Australia and the U.S.A.. Interestingly, the Australia-United Kingdom and U.S.A.-Japan convergence are two of the few examples that Greasley and Oxley (1977) and St. Aubyn (1999), respectively, find using different data. In Table 3 we show the results of applying the Engle-Granger (1987) cointegrating regression ADF test, in which the null is “no cointegration", using MacKinnon's (1991) exact critical values. We see that the only (weak) evidence of cointegration arises with the Australia-U.S.A. and New ZealandJapan pairs, and possibly for Australia-New Zealand. These are the only cases where there is (bivariate) evidence of common trends in the output data. As these country pairings do not include all of those associated with stochastic convergence above, all of these bivariate results should be treated with considerable caution.

The results of applying Johansen's (1988) likelihood ratio "trace test" to examine stochastic convergence between the five output series as a group appear in Table 4. Recalling the discussion in section 2 about the way in which this test is applied, the four inter-country (log-) differences in the data have been constructed relative to the New Zealand output series. All of these differences exhibit a trend, so following the suggestion of Franses (2001) we include a drift and trend in the cointegrating equation, and a drift but no trend in the VAR models when applying Johansen's procedure. This corrsponds to "case 4" in the EViews (1998) econometrics package. As we can see, the results are not sensitive to the lag length chosen for the VAR's, and as the number of cointegrating equations is found to be two or three (and hence less than four) this implies nonconvergence for this group of outputs. Table 5 shows the corresponding results when we use Johansen's procedure to test for common trends by examining cointegration between the actual 
(log-) levels of the five series. "Case 4" in EViews is again appropriate, and the results clearly indicate that there are three cointegrating equations. So, when considering all five countries as a group we find clear evidence of a small number of common trends in output, but no evidence of stochastic convergence.

\section{Results of Cluster Convergence Analysis}

The results of our fuzzy clustering analysis of the output data for the five countries are summarized in Figures 2 and 3, for $(c=) 2$ and $(c=) 3$ fuzzy clusters respectively. Figure 1 shows the ratio of the centres of the two fuzzy clusters (each of which are measured in 1985 constant international dollars), year by year. Figure 2 shows the ratio of the centre of the "highest" cluster to that of the "lowest", year by year, where the ordering of the clusters is again on the constant dollar scale associated with the output measurement. These ratios are unitless, of course, and this facilitates inter-year comparisons. In each case we see that there is fairly steady decline in the ratio towards unity, over time. This strongly suggests a different (non-stochastic) type of convergence - "cluster convergence" - in the outputs of the various countries over our sample period - one that is intuitively sensible in view of the output data shown in Figure 1.

It is also interesting to consider the changes that take place, year by year, in the composition of the fuzzy clusters. Recall that each country's membership of a cluster is not "crisp" - actually, each country belongs to every cluster, with some varying "degree of membership". For the purposes of the present discussion, we assign a country to the cluster for which it has the highest degree of membership, in each year, and the results appear in Table 5. Not surprisingly, and again consistent with the data in Figure 1, these results clearly show the relative rise of Japanese per capita output, and the relative fall of New Zealand and U.K. per capita outputs, over the sample period.

\section{Conclusions}

In this paper we have re-visited the issue of testing for convergence and common trends in real per capita output using historical time-series data. In doing so, our focus has been two-fold. First, we have limited ourselves to a small group of countries that traded actively with the very open New Zealand economy over the period 1950 to 1992. Thus, our emphasis has been on the possibility of convergence in the context of active international trade. Second, we have 
introduced a new way of measuring convergence in the context of time-series data, by adapting the fuzzy c-means clustering algorithm. In common with most other related studies our unit root/cointegration analysis suggests a general absence of stochastic convergence (except in a few bilateral cases), but it also suggests the existence of three common trends in the five output series. On the other hand, the fuzzy clustering analysis provides the clear impression that the different countries' outputs have become steadily more closely grouped over our time-horizon.

Recently, several authors have considered the effect of increased trade on the convergence of output across different countries. At this stage the evidence is rather mixed, and further research is certainly warranted. The fuzzy clustering methodology that we have illustrated in this paper seems to have considerable promise, and work that is in progress involves the use of this methodology to investigate the trade expansion/output convergence relationship in some detail. 


\section{References}

Barro, R. J. (1991), "Economic growth in a cross-section of countries", Quarterly Journal of Economics, CVI, 407-445.

Barro, R. J. and X. Sala-i-Martin (1991), "Convergence across states and regions", Brookings Papers on Economic Activity, 1, 107-158.

Barro, R. J. and X. Sala-i-Martin (1992), “Convergence”, Journal of Political Economy, 100, 223-251.

Barro, R. J. and X. Sala-i-Martin (1995), Economic Growth, McGraw-Hill, New York.

Baumol, W. J. (1986), "Productivity growth, convergence and welfare: What the long run data show", American Economic Review, 76, 1072-1085.

Ben-David, D. (1993), "Equalizing exchange: Trade liberalization and income convergence", Quarterly Journal of Economics, 108, 653-679.

Ben-David, D. (1996), “Trade and convergence among countries”, Journal of International Economics, 40, 279-298.

Ben-David D. and A. Kimhi (2000), "Trade and the rate of income convergence”, Working Paper 7642, NBER, Cambridge, MA.

Bernard, A. B. (1992), "Empirical implications of the convergence hypothesis", working paper, Department of Economics, MIT, Cambridge, MA.

Bernard, A. B. and S. N. Durlauf (1995), “Convergence in international output”, Journal of Applied Econometrics, 10, 97-108.

Bernard, A. B. and S. N. Durlauf (1996), "Interpreting tests of the convergence hypothesis", Journal of Econometrics, 71, 161-173.

Bezbek, J. C. (1973), Fuzzy Mathematics in Pattern Classification, Ph.D. Thesis, Applied Mathematics Center, Cornell University, Ithaca, NY.

Bezbek, J. C. (1981), Pattern Recognition With Fuzzy Objective Function Algorithms, Plenum Press, New York.

Cellini, R. and A. E. Scorcu (2000), "Segmented stochastic convergence across the G-7 countries", Empirical Economics, 25, 463-474.

Cheung, Y-W., M. D. Chinn and T. Tran (1995), "How sensitive are trends to data definitions? Results for East Asian countries", Applied Economics Letters, 2, 1-6.

Dickey, D. A. and W. A. Fuller (1979), "Distribution of the estimators for autoregressive time series with a unit root", Journal of the American Statistical Association, 74, 427-431. 
Dickey, D. A. and W. A. Fuller (1981), "Likelihood ratio statistics for autoregressive time series with a unit root", Econometrica, 49, 1057-1072.

Dods, J. L. and D. E. A. Giles (1995), “Alternative strategies for 'augmenting' the Dickey-Fuller test: Size-robstness in the face of pre-testing”, Journal of Statistical Computation and Simulation, 53, 243-258.

Dolado, J. J., T. Jenkinson and S. Sosvilla-Rivero (1990), “Cointegration and unit roots”, Journal of Economic Surveys, 4, 249-273.

Dowrick, S. and D.-T. Nguyen (1989), “OECD comparative economic growth 1950-1985: Catch up and convergence”, American Economic Review, 79, 1010-1030.

Dunn, J. C. (1974), "Well separated clusters and optimal fuzzy partitions”, Journal of Cybernetics, 4, 95-104.

Dunn, J. C. (1977), "Indices of partition fuzziness and the detection of clusters in large data sets", in M. Gupta and G. Seridis (eds.), Fuzzy Automata and Decision Processes, Elsevier, New York.

Durlauf, S. N. And P. A. Johnson (1995), "Multiple regimes and cross-country growth behaviour", Journal of Applied Economics, 10, 365-384.

Durlauf, S. N. And D. T. Quah (1999), "The new empirics of economic growth", in J. B. Taylor and M. Woodford (eds.), Handbook of Macroeconomics, Vol 1A, Elsevier, Amsterdam, 235-308.

Engle, R. F. and Granger, C. W. J. (1987), “Co-integration and error correction: representation, estimation, and testing", Econometrica, 55, 251-276.

EViews (1998), EViews 3 User's Guide, Quantitative Micro Software, Irvine CA.

Franses, P. H. (2001), "How to deal with intercept and trend in practical cointegration analysis?", Applied Economics, 33, 577-579.

Giles, D.E.A. and R. Draeseke (2001), "Econometric modelling using pattern recognition via the fuzzy c-means algorithm", to appear in D.E.A. Giles (ed.), Computer-Aided Econometrics, Marcel Dekker, New York. (Currently available as Econometrics Working Paper EWP0101, Department of Economics, University of Victoria, and downloadable from http://www.uvic.ca/econ/ewp0101.pdf)

Greasley, D. and L. Oxley (1997), "Time-series based tests of the convergence hypothesis: some positive results", Economics Letters, 56, 143-147.

Gregory, A. W. and B. E. Hansen (1996), "Residual-based tests for cointegration in models with regime shifts", Journal of Econometrics, 70, 99-126. 
Hobijn, B. and P. H. Franses (1999), “Are living standards converging?”, Report 105, Econometric Institute, Erasmus University, Rotterdam.

Hornok, A. and R. Larsson (2000), "The finite sample distribution of the KPSS test", Econometrics Journal, 3, 108-121.

Johansen, S. (1988), "Statistical analysis of cointegration vectors", Journal of Economic Dynamics and Control, 12, 231-254.

Johansen, S. (1995), Likelihood-Based Inference in Cointegrated Vector Autoregressive Models, Oxford, Oxford University Press.

Kwiatowski, D., P. C. B. Phillips, P. Schmidt, and Y. Shin (1992), “Testing the null hypothesis of stationarity against the alternative of a unit root: How sure are we that economic time series have a unit root?", Journal of Econometrics, 54, 159-178.

Lucas, R. E. (1988), “On the mechanics of economic development”, Journal of Monetary Economics, 22, 3-42.

MacKinnon, J. G. (1991), “Critical values for co-integration tests”, in R. F. Engle and C. W. J. Granger (eds.), Long-Run Economic Relationships, Cambridge University Press, Cambridge.

MacQueen, J. (1967), "Some methods for classification and analysis of multivariate observations", in J. M. Le Cam and J. Neyman (eds.), Proceedings of the $5^{\text {th }}$ Berkeley Symposium in Mathematical Statistics and Probability, University of California Press, Berkeley CA, 281-297.

Mankiw, N. G., D. Romer, and D. N. Weil (1992), “A contribution to the empirics of economic growth", Quarterly Journal of Economics, CVII, 407-437.

Meyer, B. D. (1994), "Natural and quasi-experiments in economics", Technical Paper \#170, NBER, Cambridge MA.

O'Rourke, K. (1996), “Trade, migration and convergence: An historical perspective”, CEPR Discussion Paper No. 1319.

Perron, P. (1989), "The great crash, the oil price shock, and the unit root hypothesis", Econometrica, 99, 1361-1401.

Quah, D. (1993), "Empirical cross-section dynamics in economic growth", European Economic Review, 37, 426-434.

Romer, P. M. (1986), “Increasing returns and long run growth”, Journal of Political Economy, 94, 1002-1037.

Ruspini, E. (1970), “Numerical methods for fuzzy clustering”, Information Science, 2, 319-350. 
Sachs, J. and A. Warner (1995), "Economic reform and the process of global integration", Brookings Papers on Economic Activity, 1, 1-118.

SHAZAM (2001), SHAZAM Econometrics Package, User's Guide, Version 9, Northwest Econometrics, Vancouver, B.C..

Slaughter, M. J. (1997), "Per capita income convergence and the role of international trade", American Economic Review, 87, 194-199.

Slaughter, M. J. (1998), "International trade and per capita income convergence: A difference-indifferences analysis", Working Paper 6557, NBER, Cambridge, MA.

Solow, R. M. (1956), “A contribution to the theory of economic growth”, Quarterly Journal of Economics, LXX, 65-94.

St. Aubyn, M. (1999), “Convergence across industrialized countries (1890-1989): New results using time series methods", Empirical Economics, 24, 23-44.

Summers, R. and A. Heston (1995), The Penn World Tables, Version 5.6, National Bureau of Economic Research, Cambridge MA. (Downloaded from CHASS Computing Centre, University of Toronto, http://datacentre.epas.utoronto.ca:5680/pwt/ )

Zadeh, L. A. (1965), "Fuzzy sets", Information and Control, 8, 338-353. 
Figure 1. Real per capita Output - All Countries

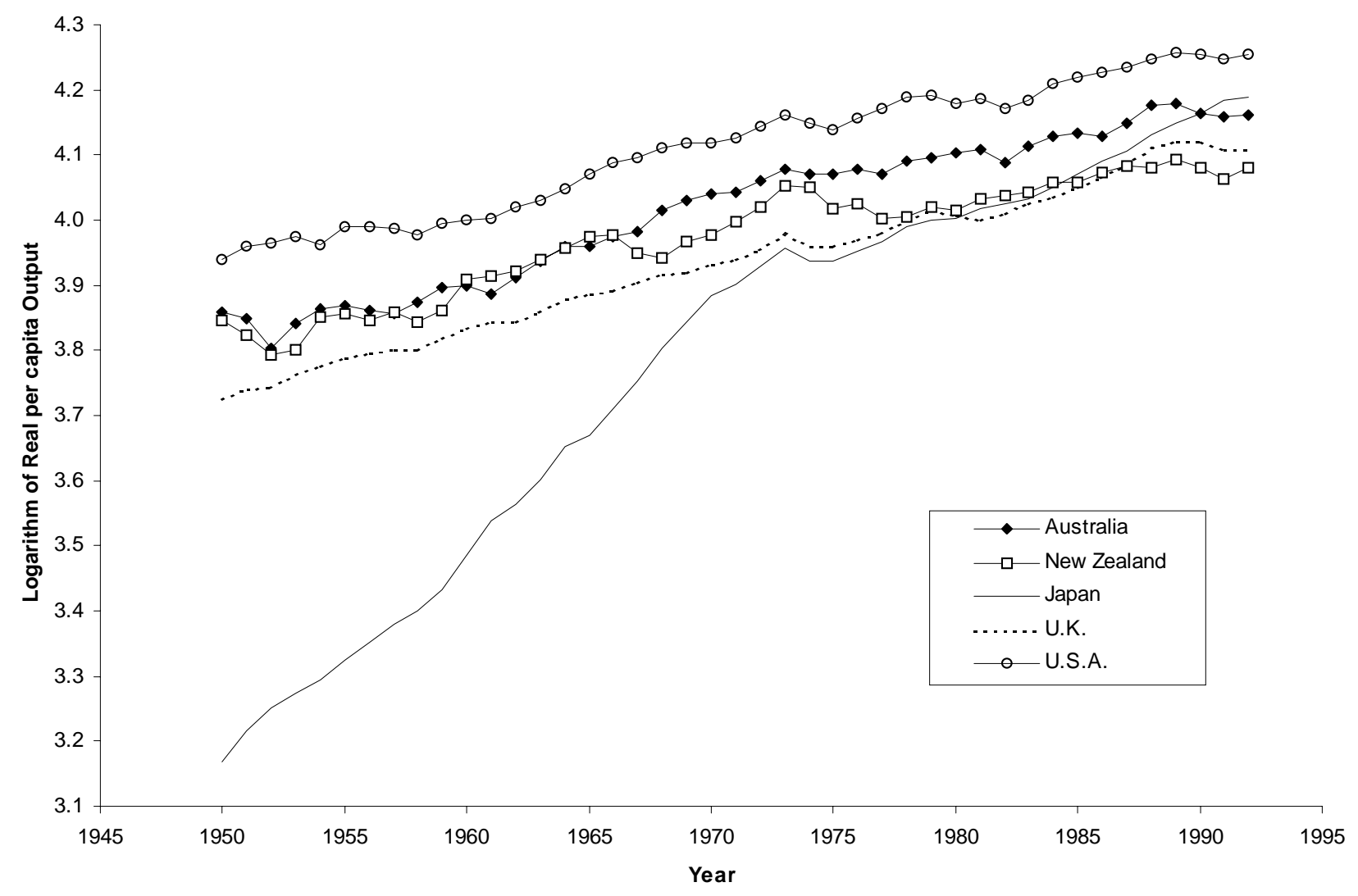


Figure 2. Ratio of Fuzzy Cluster Centres

$$
(\mathrm{c}=2)
$$

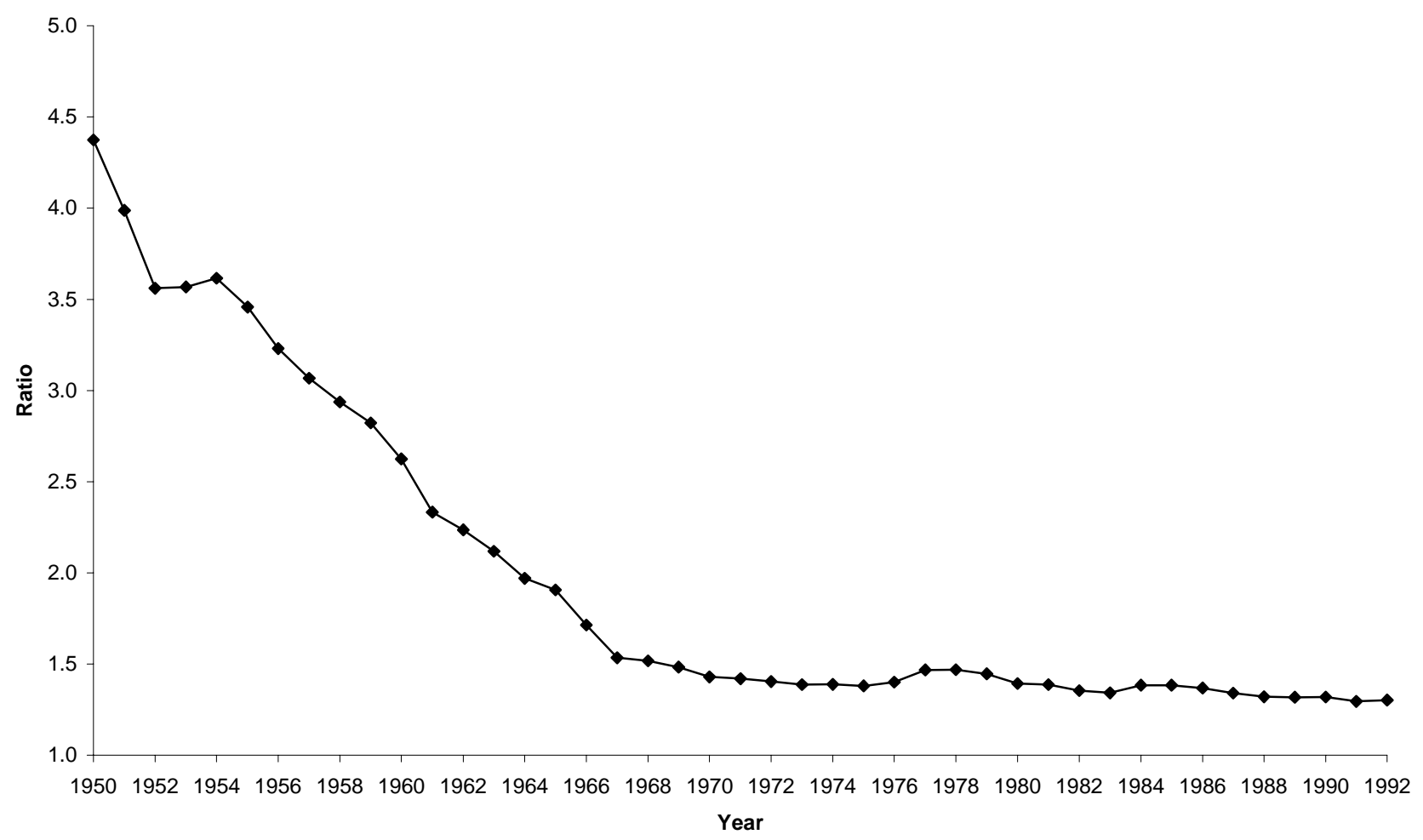

Figure 3. Ratio of Largest to Smallest Fuzzy Cluster Centres $(c=3)$

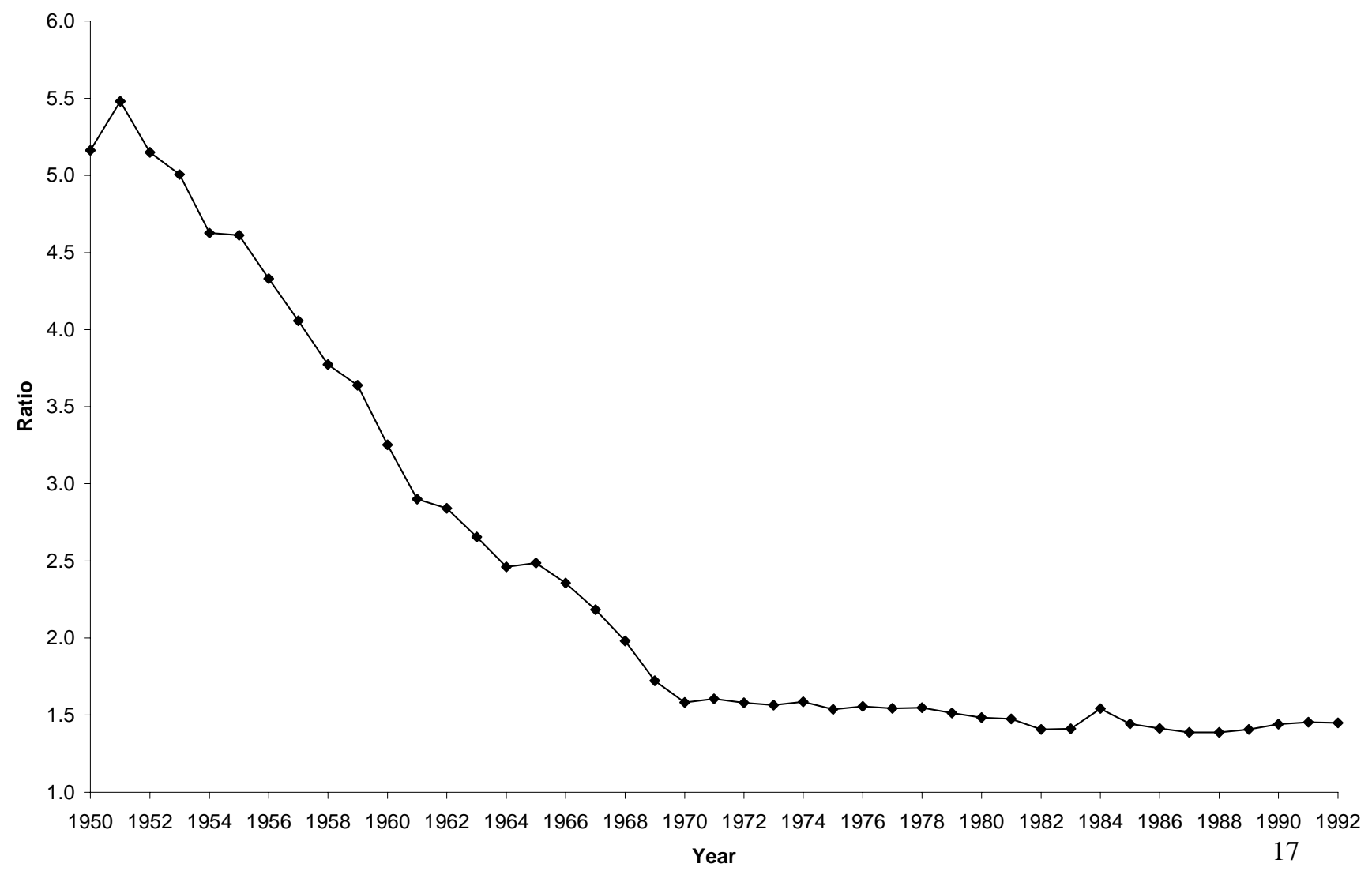


Table 1. Unit root test results (logarithms of the data)

a. Augmented Dickey-Fuller tests

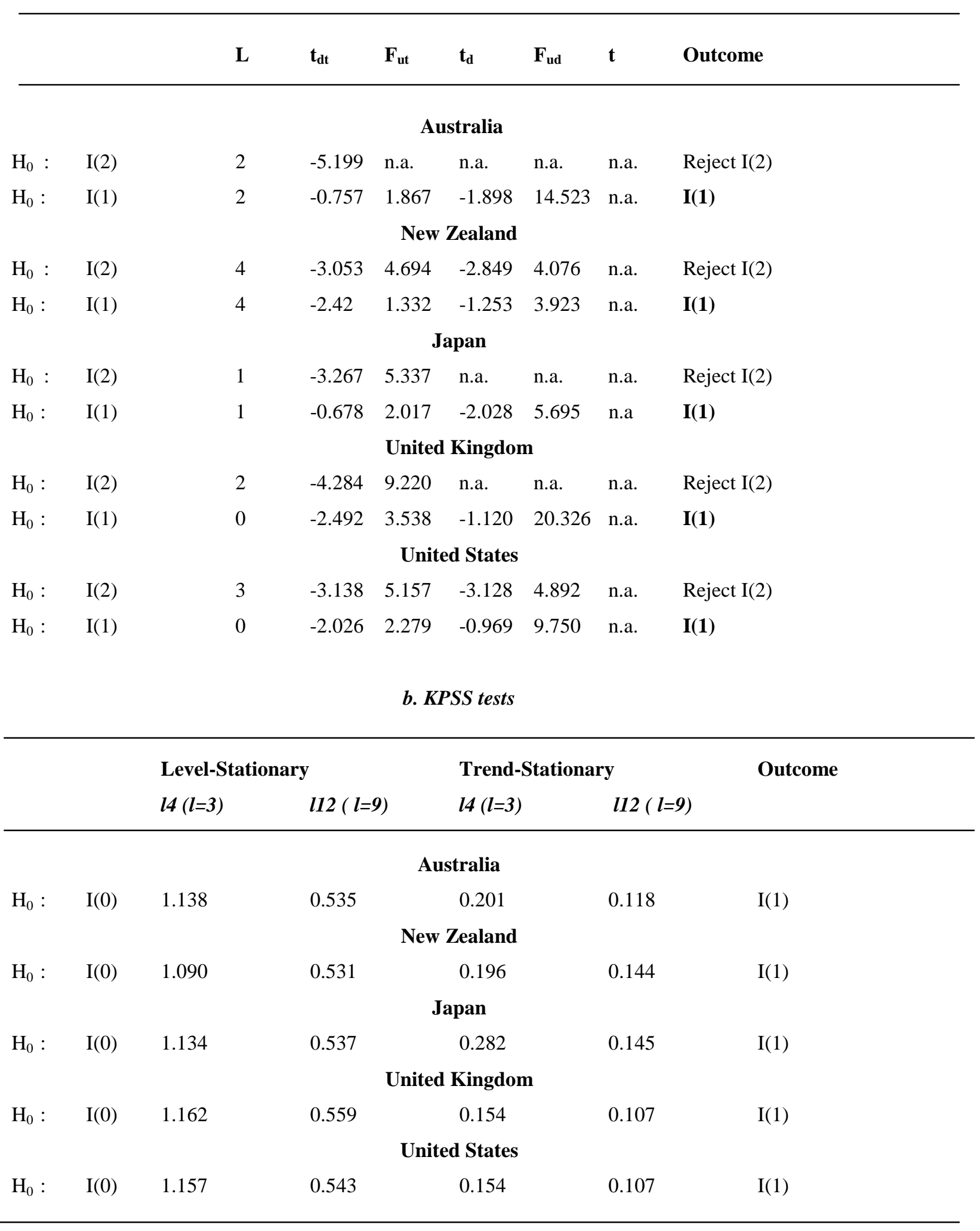


Table 2. Pair-wise convergence test results (logarithms of the data)

a. Augmented Dickey-Fuller tests

\begin{tabular}{|c|c|c|c|c|c|c|c|c|}
\hline & & $\mathbf{L}$ & $\mathbf{t}_{\mathrm{dt}}$ & $\mathbf{F}_{\text {ut }}$ & $\mathbf{t}_{d}$ & $\mathbf{F}_{\mathbf{u d}}$ & $\mathbf{t}$ & Outcome \\
\hline \multicolumn{9}{|c|}{ Australia } \\
\hline N.Z. & & 0 & -3.144 & 4.956 & -1.731 & 1.659 & -0.651 & $\mathbf{I}(\mathbf{1})$ \\
\hline Japan & & 2 & -0.775 & 3.313 & -2.610 & 15.108 & n.a. & $?$ \\
\hline U.K. & & 2 & -0.700 & 0.878 & -0.737 & 0.474 & -0.774 & $\mathbf{I}(\mathbf{1})$ \\
\hline U.S.A & & 2 & -2.760 & 4.893 & -2.595 & 3.833 & n.a. & $?$ \\
\hline \multicolumn{9}{|c|}{ New Zealand } \\
\hline Japan & & 0 & -1.857 & 4.186 & -2.590 & 18.990 & n.a. & $?$ \\
\hline U.K. & & 4 & -1.839 & 1.899 & -0.458 & 1.142 & -1.487 & $\mathbf{I}(\mathbf{1})$ \\
\hline U.S.A. & & 0 & -2.782 & 3.877 & -2.469 & 3.275 & 0.150 & $\mathbf{I}(\mathbf{1})$ \\
\hline \multicolumn{9}{|c|}{ Japan } \\
\hline U.K. & & 1 & -0.985 & 1.417 & -1.653 & 3.418 & -2.017 & $\mathbf{I}(0)=$ convergence \\
\hline U.S.A. & & 0 & -1.637 & 2.736 & -2.151 & 3.463 & -2.649 & $\mathbf{I}(0)=$ convergence \\
\hline \multicolumn{9}{|c|}{ United Kingdom } \\
\hline U.S.A. & & 0 & -2.288 & 2.621 & -1.602 & 1.808 & -1.190 & $\mathbf{I}(\mathbf{1})$ \\
\hline \multicolumn{9}{|c|}{ b. KPSS tests } \\
\hline \multicolumn{5}{|c|}{ Level-Stationary } & \multicolumn{3}{|c|}{ Trend-Stationary } & Outcome \\
\hline & $14(l=3)$ & & $l 12(l=$ & & $14(l=3)$ & & $l 12(l=9)$ & \\
\hline \multicolumn{9}{|c|}{ Australia } \\
\hline N.Z. & 0.915 & & 0.482 & & 0.089 & & 0.104 & $?$ \\
\hline Japan & 1.119 & & 0.534 & & 0.292 & & 0.150 & $\mathbf{I}(\mathbf{1})$ \\
\hline U.K. & 0.196 & & 0.124 & & 0.186 & & 0.112 & $\mathbf{I}(0)=$ convergence \\
\hline U.S.A. & 0.810 & & 0.445 & & 0.149 & & 0.138 & $\mathbf{I}(\mathbf{1})$ \\
\hline \multicolumn{9}{|c|}{ New Zealand } \\
\hline Japan & 1.137 & & 0.539 & & 0.268 & & 0.145 & $\mathbf{I}(\mathbf{1})$ \\
\hline U.K. & 0.904 & & 0.512 & & 0.170 & & 0.151 & $\mathbf{I}(\mathbf{1})$ \\
\hline U.S.A. & 0.535 & & 0.394 & & 0.104 & & 0.131 & $?$ \\
\hline \multicolumn{9}{|c|}{ Japan } \\
\hline U.K. & 1.086 & & 0.513 & & 0.283 & & 0.146 & $\mathbf{I}(\mathbf{1})$ \\
\hline U.S.A. & 1.107 & & 0.529 & & 0.287 & & 0.150 & $\mathbf{I}(\mathbf{1})$ \\
\hline \multicolumn{9}{|c|}{ United Kingdom } \\
\hline U.S.A. & 0.708 & & 0.447 & & 0.142 & & 0.099 & $\mathbf{I}(\mathbf{1})$ \\
\hline
\end{tabular}


Table 3. Pair-wise common trends test results (logarithms of the data)

Engle-Granger cointegration tests

No Trend in Cointegrating Regression
With Trend in Cointegrating Regression

\section{Australia}

$\begin{array}{ll}\text { N.Z. } & -3.038 \\ \text { Japan } & -1.723 \\ \text { U.K. } & -0.959 \\ \text { U.S.A } & -3.676^{*}\end{array}$

$\begin{array}{ll} & \\ \text { Japan } & -3.327^{*} \\ \text { U.K. } & -1.802 \\ \text { U.S.A. } & -2.786\end{array}$

$\begin{array}{ll}\text { U.K. } & -1.737 \\ \text { U.S.A. } & -2.276\end{array}$

U.S.A. $\quad-2.271$

\section{United Kingdom}

New Zealand

$$
\begin{aligned}
& -3.027 \\
& -2.269 \\
& -0.856 \\
& -3.218
\end{aligned}
$$

$-3.333$

$-2.000$

$-2.699$

\section{Japan}

$-1.618$

$-2.066$

$-2.683$

Note: * Significant at the $10 \%$ level. This implies cointegration, and hence the existence of common trends. 
Table 4. Group convergence trends test results (logarithms of the data)

$\underline{\text { VAR lag-length }=1}$

\begin{tabular}{lllll} 
Eigenvalue & $\begin{array}{l}\text { Trace } \\
\text { Statistic }\end{array}$ & $\begin{array}{l}\text { 5 Percent } \\
\text { Critical Value }\end{array}$ & $\begin{array}{l}\text { 1 Percent } \\
\text { Critical Value }\end{array}$ & $\begin{array}{l}\text { Hypothesized } \\
\text { No. of CE(s) }\end{array}$ \\
\hline 0.764411 & 108.3134 & 62.99 & 70.05 & None ** \\
0.460274 & 49.04098 & 42.44 & 48.45 & At most 1 ** \\
0.343024 & 23.75650 & 25.32 & 30.45 & At most 2 \\
0.147276 & 6.532113 & 12.25 & 16.26 & At most 3
\end{tabular}

$\underline{V A R}$ lag-length $=2$

\begin{tabular}{lllll} 
Eigenvalue & $\begin{array}{l}\text { Trace } \\
\text { Statistic }\end{array}$ & $\begin{array}{l}\text { 5 Percent } \\
\text { Critical Value }\end{array}$ & $\begin{array}{l}\text { 1 Percent } \\
\text { Critical Value }\end{array}$ & $\begin{array}{l}\text { Hypothesized } \\
\text { No. of CE(s) }\end{array}$ \\
\hline 0.587624 & 84.88103 & 62.99 & 70.05 & None ** \\
0.421204 & 49.44828 & 42.44 & 48.45 & At most 1 ** \\
0.376197 & 27.57604 & 25.32 & 30.45 & At most 2* \\
0.195456 & 8.699186 & 12.25 & 16.26 & At most 3
\end{tabular}

$\underline{V A R}$ lag-length $=3$

\begin{tabular}{lllll} 
Eigenvalue & $\begin{array}{l}\text { Trace } \\
\text { Statistic }\end{array}$ & $\begin{array}{l}\text { 5 Percent } \\
\text { Critical Value }\end{array}$ & $\begin{array}{l}\text { 1 Percent } \\
\text { Critical Value }\end{array}$ & $\begin{array}{l}\text { Hypothesized } \\
\text { No. of CE(s) }\end{array}$ \\
\hline 0.570254 & 80.45461 & 62.99 & 70.05 & None ** \\
0.421421 & 47.51675 & 42.44 & 48.45 & At most $1 *$ \\
0.321696 & 26.17674 & 25.32 & 30.45 & At most 2* \\
0.246509 & 11.03851 & 12.25 & 16.26 & At most 3
\end{tabular}

Notes: "CE" denotes "Cointegrating Equation".

$*(* *)$ denotes rejection of the null hypothesis at 5\% (1\%) significance level. 
Table 5. Group common trends test results (logarithms of the data)

$\underline{V A R}$ lag-length $=1$

\begin{tabular}{lllll} 
Eigenvalue & $\begin{array}{l}\text { Trace } \\
\text { Statistic }\end{array}$ & $\begin{array}{l}\text { 5 Percent } \\
\text { Critical Value }\end{array}$ & $\begin{array}{l}\text { 1 Percent } \\
\text { Critical Value }\end{array}$ & $\begin{array}{l}\text { Hypothesized } \\
\text { No. of CE(s) }\end{array}$ \\
\hline 0.813485 & 140.1672 & 87.31 & 96.58 & None ** \\
0.478535 & 71.31824 & 62.99 & 70.05 & At most $1 * *$ \\
0.382243 & 44.62260 & 42.44 & 48.45 & At most 2 $*$ \\
0.357933 & 24.87452 & 25.32 & 30.45 & At most 3 \\
0.150947 & 6.708980 & 12.25 & 16.26 & At most 4
\end{tabular}

$\underline{V A R}$ lag-length $=2$

\begin{tabular}{lllll} 
Eigenvalue & $\begin{array}{l}\text { Trace } \\
\text { Statistic }\end{array}$ & $\begin{array}{l}\text { 5 Percent } \\
\text { Critical Value }\end{array}$ & $\begin{array}{l}\text { 1 Percent } \\
\text { Critical Value }\end{array}$ & $\begin{array}{l}\text { Hypothesized } \\
\text { No. of CE(s) }\end{array}$ \\
\hline 0.692973 & 114.7872 & 87.31 & 96.58 & None ** \\
0.455066 & 67.55439 & 62.99 & 70.05 & At most $1 *$ \\
0.378755 & 43.27078 & 42.44 & 48.45 & At most 2* \\
0.301528 & 24.22961 & 25.32 & 30.45 & At most 3 \\
0.218766 & 9.875224 & 12.25 & 16.26 & At most 4
\end{tabular}

$\underline{V A R}$ lag-length $=3$

\begin{tabular}{lllll} 
Eigenvalue & $\begin{array}{l}\text { Trace } \\
\text { Statistic }\end{array}$ & $\begin{array}{l}\text { 5 Percent } \\
\text { Critical Value }\end{array}$ & $\begin{array}{l}\text { 1 Percent } \\
\text { Critical Value }\end{array}$ & $\begin{array}{l}\text { Hypothesized } \\
\text { No. of CE(s) }\end{array}$ \\
\hline 0.802888 & 133.3293 & 87.31 & 96.58 & None ** \\
0.501232 & 69.99391 & 62.99 & 70.05 & At most $1 *$ \\
0.374928 & 42.86493 & 42.44 & 48.45 & At most 2* \\
0.300118 & 24.53926 & 25.32 & 30.45 & At most 3 \\
0.238426 & 10.62235 & 12.25 & 16.26 & At most 4
\end{tabular}

Notes: "CE" denotes "Cointegrating Equation".

$*(* *)$ denotes rejection of the null hypothesis at $5 \%(1 \%)$ significance level. 
Table 6. Composition of fuzzy clusters

\begin{tabular}{|c|c|c|c|c|c|c|c|c|}
\hline \multicolumn{9}{|c|}{ a. $\quad c=2$} \\
\hline Year & $C 1$ & $C 2$ & Year & $C 1$ & $C 2$ & Year & $C 1$ & $C 2$ \\
\hline 1950 & $\mathrm{~J}$ & A N K U & 1964 & $\mathrm{~J}$ & A N K U & 1978 & A N J K & $\mathrm{U}$ \\
\hline 1951 & $\mathrm{~J}$ & A N K U & 1965 & $\mathrm{~J}$ & A N K U & 1979 & A N J K & $\mathrm{U}$ \\
\hline 1952 & $\mathrm{~J}$ & A N K U & 1966 & J K & $\mathrm{ANU}$ & 1980 & N Z K & A U \\
\hline 1953 & $\mathrm{~J}$ & A N K U & 1967 & A N J K & $\mathrm{U}$ & 1981 & N Z K & A U \\
\hline 1954 & $\mathrm{~J}$ & A N K U & 1968 & A N J K & $\mathrm{U}$ & 1982 & A N J K & $\mathrm{U}$ \\
\hline 1955 & $\mathrm{~J}$ & A N K U & 1969 & A N J K & $\mathrm{U}$ & 1983 & N Z K & $\mathrm{A} \mathrm{U}$ \\
\hline 1956 & $\mathrm{~J}$ & A N K U & 1970 & N J K & $\mathrm{A} \mathrm{U}$ & 1984 & A N J K & $\mathrm{U}$ \\
\hline 1957 & $\mathrm{~J}$ & A N K U & 1971 & A N J K & $\mathrm{U}$ & 1985 & A N J K & $\mathrm{U}$ \\
\hline 1958 & $\mathrm{~J}$ & A N K U & 1972 & A N J K & $\mathrm{U}$ & 1986 & A N J K & $\mathrm{U}$ \\
\hline 1959 & $\mathbf{J}$ & A N K U & 1973 & A N J K & $\mathrm{U}$ & 1987 & A N J K & $\mathrm{U}$ \\
\hline 1960 & $\mathrm{~J}$ & A N K U & 1974 & J K & A N U & 1988 & A N J K & $\mathrm{U}$ \\
\hline 1961 & $\mathrm{~J}$ & A N K U & 1975 & N Z K & A U & 1989 & A N J K & $\mathrm{U}$ \\
\hline 1962 & $\mathrm{~J}$ & A N K U & 1976 & J K & A N U & 1990 & A N J K & $\mathrm{U}$ \\
\hline \multirow[t]{2}{*}{1963} & $\mathrm{~J}$ & A N K U & 1977 & A N J K & $\mathrm{U}$ & 1991 & N K & A J U \\
\hline & & & & & & 1992 & A N K & J U \\
\hline \multicolumn{9}{|c|}{$\underline{b .} c=3$} \\
\hline$\underline{\text { Year }}$ & $C 1$ & $C 2$ & C3 & Year & $C 1$ & $C 2$ & C3 & \\
\hline 1950 & $\mathrm{~J}$ & N K & $\mathrm{AU}$ & 1972 & $\mathrm{~J} \mathrm{~K}$ & A N & $\mathrm{U}$ & \\
\hline 1951 & $\mathrm{~J}$ & A N K & $\mathrm{U}$ & 1973 & $\mathrm{~J} \mathrm{~K}$ & A N & $\mathrm{U}$ & \\
\hline 1952 & $\mathbf{J}$ & A N K & $\mathrm{U}$ & 1974 & J K & A N & $\mathrm{U}$ & \\
\hline 1953 & $\mathrm{~K}$ & A N J & $\mathrm{U}$ & 1975 & $\mathrm{~J} \mathrm{~K}$ & A N & $\mathrm{U}$ & \\
\hline 1954 & $\mathrm{~J}$ & A N K & $\mathrm{U}$ & 1976 & $\mathrm{~J} \mathrm{~K}$ & A N & $\mathrm{U}$ & \\
\hline 1955 & $\mathrm{~K}$ & A N J & $\mathrm{U}$ & 1977 & N J K & A & $\mathrm{U}$ & \\
\hline 1956 & $\mathrm{~K}$ & A N J & $\mathrm{U}$ & 1978 & N J K & A & $\mathrm{U}$ & \\
\hline 1957 & $\mathrm{~J}$ & A N K & $\mathrm{U}$ & 1979 & N J K & A & $\mathrm{U}$ & \\
\hline 1958 & $\mathrm{~K}$ & A N J & $\mathrm{U}$ & 1980 & N J K & A & $\mathrm{U}$ & \\
\hline 1959 & $\mathrm{~J}$ & A N K & $\mathrm{U}$ & 1981 & N J K & A & $\mathrm{U}$ & \\
\hline 1960 & $\mathrm{~K}$ & A N J & $\mathrm{U}$ & 1982 & N J K & A & $\mathrm{U}$ & \\
\hline 1961 & $\mathbf{J}$ & A N K & $\mathrm{U}$ & 1983 & N J K & A & $\mathrm{U}$ & \\
\hline 1962 & $\mathrm{~J}$ & A N K & $\mathrm{U}$ & 1984 & N J K & A & $\mathrm{U}$ & \\
\hline 1963 & $\mathrm{~J}$ & A N K & $\mathrm{U}$ & 1985 & N J K & A & $\mathrm{U}$ & \\
\hline 1964 & $\mathrm{~J}$ & A N K & $\mathrm{U}$ & 1986 & N J K & A & $\mathrm{U}$ & \\
\hline 1965 & $\mathrm{~J}$ & A N K & $\mathrm{U}$ & 1987 & N J K & A & $\mathrm{U}$ & \\
\hline 1966 & $\mathrm{~J}$ & A N K & $\mathrm{U}$ & 1988 & N J K & A & $\mathrm{U}$ & \\
\hline 1967 & $\mathbf{J}$ & A N K & $\mathrm{U}$ & 1989 & N K & A J & $\mathrm{U}$ & \\
\hline 1968 & $\mathbf{J}$ & A N K & $\mathrm{U}$ & 1990 & N K & A J & $\mathrm{U}$ & \\
\hline 1969 & $\mathrm{~J} \mathrm{~K}$ & A N & $\mathrm{U}$ & 1991 & N K & A J & $\mathrm{U}$ & \\
\hline 1970 & N J K & A & $\mathrm{U}$ & 1992 & N K & A J & $\mathrm{U}$ & \\
\hline 1971 & J K & A N & $\mathrm{U}$ & & & & & \\
\hline
\end{tabular}

Note: Ci denotes cluster “i”; A = Australia; $\mathrm{N}$ = New Zealand; J = Japan; $\mathrm{K}=$ U.K.; U = U.S.A. 